\title{
BMJ Open Support for infants and young people with sight loss: a qualitative study of sight impairment certification and referral to education and social care services
}

\author{
Tammy Boyce, ${ }^{1}$ Annegret Dahlmann-Noor, ${ }^{2}$ Richard Bowman, ${ }^{3,4}$ Sue Keil ${ }^{5}$
}

To cite: Boyce T, DahlmannNoor A, Bowman R, et al. Support for infants and young people with sight loss: a qualitative study of sight impairment certification and referral to education and social care services. BMJ Open 2015;5:e009622. doi:10.1136/bmjopen-2015009622

- Prepublication history for this paper is available online. To view these files please visit the journal online (http://dx.doi.org/10.1136/ bmjopen-2015-009622).

Received 4 August 2015 Revised 15 October 2015 Accepted 13 November 2015

\section{CrossMark}

${ }^{1}$ Cardiff, UK

${ }^{2}$ NIHR Biomedical Research Centre at Moorfields Eye Hospital NHS Foundation Trust and UCL Institute of Ophthalmology, London, UK ${ }^{3}$ International Centre for Eye Health, London School of Hygiene and Tropical Medicine, London, UK ${ }^{4}$ Institute of Child Health, London, UK

${ }^{5}$ Royal National Institute of Blind People (RNIB),

Birmingham, UK

Correspondence to

Dr Sue Keil;

Sue.Keil@rnib.org.uk

\section{ABSTRACT}

Objectives: To examine the experience of infants, children and their parents, the role of ophthalmologists and other health, social care and education professionals in the certification and registration processes and examine the relationship between certification and referrals and pathways to support.

Design: Qualitative study.

Setting: Telephone interviews with health and, social care professionals, qualified teachers of children and young people with vision impairment (QTVIs) and parents of infants/children in England.

Participants: 52 health, social care and education professionals who are part of the certification or registration process. 26 parents of infants and children with vision impairment.

Results: Referrals to education do not require a Certificate of Vision Impairment (CVI); however, the majority of parents received support from education and social services only after an offer of the CVI, which was often dependent on having a formal diagnosis. Parents stated they wanted support sooner, particularly parents of children with additional complex needs who experienced longer delays. Areas with multidisciplinary teams and support roles such as eye clinic liaison officers (ECLOs) appeared to have more reliable referral pathways.

Conclusions: For infants and children with vision impairment, there should be a consistent mechanism for triggering education and social care support even with uncertainty about diagnosis and/or prognosis. All professionals involved in the certification and registration processes (ophthalmologists, optometrists, ECLOs, orthoptists, social workers, QTVIs) can better communicate the value and benefits of certification and registration.

\section{INTRODUCTION}

The purpose of the Certificate of Vision Impairment (CVI) for both children and adults is to provide a reliable route for

\section{Strengths and limitations of this study}

- The research is the first study to analyse the processes of certification and registration in infants and children and the various health, social care and education professions involved.

- The experience of parents from across England shows wide variation in the certification and registration processes, with examples of good and poor practice.

- The article offers examples of good practice to improve consistency of the certification and registration processes.

- The number of participants was small, so findings should be considered indicative; however, saturation/repetition levels were reached in all three interview groups, suggesting confidence in the findings.

- Parents of infants and children certified came from all areas in England and did not reflect the areas where professionals worked. Further research is needed to explore both the provision and experience of care in specific areas; however, this research was still able to identify key themes arising from each interview cohort.

someone with sight loss to be brought to the attention of social care. Certification and registration is transformative for adults as the referral to social services and the support triggered substantially improves their lives. ${ }^{1}$ While for infants and children, social services often have an important role to play, and registration also brings financial and practical benefits to families, the main provider of support is the local authority specialist vision impairment (VI) education service. Early assessment and interventions (eg, lowvision aids) can decrease risks of delayed development in motor, cognitive, language and social domains. ${ }^{2-7}$ In the UK, qualified teachers of children and young people with 
vision impairment (QTVIs) most commonly provide training and support to enable parents to assist their child's early development.

Information is parents' greatest need at the period of establishing a diagnosis of their child's ophthalmic disorder. ${ }^{8}$ During this critical period when an infant/ child's VI is being diagnosed, parents state they want support to both accept their infant/child's sight loss and to learn how to maximise the remaining vision and develop adaptive skills. ${ }^{9-11}$ However, research consistently finds parents do not receive this information from health professionals at an early stage, leaving parents frustrated $^{12}$ and children with delayed development. ${ }^{13} 14$

Through interviews with health and social care and education professionals and parents, this research explores what triggers referral for support and whether clinicians depend on a firm diagnosis or a CVI to act as a trigger, or needs of/requests from patients and parents. In addition, it examines the impact of waiting for referrals to education and provides examples of good practice and identifies ways of ensuring prompt referrals. The research follows on from previous research on adults and the CVI and registration process ${ }^{1}$ (see box 1), whereas the aim of this research was to examine issues related to the certification and registration processes in infants and young people.

\section{MATERIALS AND METHODS}

\section{Sample}

The purposive sample seeks to provide an overview of the certification and registration processes in five National Health Service (NHS) areas. The study of health, social care and education professionals was conducted in five areas in England identified as having differences in sight loss registration rates (lower, average or higher registration rates than might be expected for the size of the child population in that area $)^{21}$ and whether or not they employed specialist paediatric ophthalmologists. We purposely selected areas that would provide us with, as Morse ${ }^{22}$ states, 'excellent examples' as well as more ordinary or common practices. Purposive sampling is based on knowledge of a population. ${ }^{23}$ In this research, those professionals involved in certifying and supporting infants and children with VI and parents of children who are certified as severely sight impaired or sight impaired were deliberately selected for interview.

Hospital consultants were identified by Royal National Institute of Blind People (RNIB) or the advisory group; subsequent healthcare staff were identified by the consultants first contacted. The research advisory group included health, education and social care professionals. Education (QTVIs) and social care interviewees were identified by healthcare professionals or one of the

\section{Box 1 The certification and registration processes}

Certification and registration are two separate processes and involve a number of stages. First, the Certificate of Vision Impairment (CVI) is completed by a consultant ophthalmologist who establishes a child's eligibility for certification as either sight impaired (SI) or severely sight impaired (SSI). The completed CVI is then sent to the local Social Services Department who 'offer' registration, as it is a voluntary choice. Registration offers practical and financial benefits and concessions. ${ }^{15}$ The CVI should act as a referral for a social care assessment, and where eligible, the offer of support.

Support offered by education follows a separate referral pathway and is not dependant on certification or registration but based on a child's need.

The UK Department of Health recommends that infants and young children who have congenital ocular abnormalities leading to visual defects should be certified as SI unless they are obviously SSI. ${ }^{16}$ Children aged 4 and over should be certified as SSI or SI according to their binocular corrected vision. No other UK-specific guidelines exist for children.

Between 1982 and 2011, there has been more than twofold increase in new blind and partial-sight registration in children in England. ${ }^{17}$ However, the rise in registration rates is inconsistent across England. ${ }^{18}$ The cause of this irregularity is estimated to be due to both the 'combination of a genuinely higher prevalence of visual impairment locally and under-reporting of visual impairment nationally'. ${ }^{19}$

The criteria for certification as blind or partially sighted are defined by the Department of Health. Generally, to be certified (and subsequently registered) as SSI (blind) a person's sight needs to fall into one of the following categories, while wearing glasses or contact lenses that they need:

- Visual acuity of less than $3 / 60$ with a full visual field

- Visual acuity of between $3 / 60$ and $6 / 60$ with a moderate reduction of field of vision, such as tunnel vision

- Visual acuity of $6 / 60$ or above, but with a very reduced field of vision especially if a lot of sight is missing especially in the lower part of the field

To be certified (and subsequently registered) as SI (partially sighted) a person's sight has to fall into one of the following categories, while wearing glasses or contact lenses that they need:

- Visual acuity of $3 / 60$ to $6 / 60$ with a full field of vision

- Visual acuity of up to $6 / 24$ with a moderate reduction of field of vision or with a central part of vision that is clouded or blurry

- Visual acuity of up to 6/18 or better if a large part of their field of vision, for example, a whole half of their vision, is missing or a lot of their peripheral vision is missing.

The only additional advice with regard to infants and young people are:

- Infants and young children who have congenital ocular abnormalities leading to visual defects should be certified as SI unless they are obviously severely sight impaired.

Children aged 4 and over should be certified as severely sight impaired or sight impaired according to the binocular corrected vision. ${ }^{20}$ 
authors. Parents were recruited via invitation calls sent from RNIB and Action for Blind People (posted on their websites) and letters sent by interviewed QTVIs. The request for interviews was also placed on social media websites of parent support groups-this was beyond our control but was very welcome as it led to a number of parents being interviewed. Parents were recruited from across the whole of England.

After examination of the National Research Ethics Framework $^{24}$ the research was deemed a service evaluation and ethics approval was not necessary. None of the parental participants were identified or approached via NHS; instead, we used membership of charities and patient support organisations. Informed consent was obtained by all participants at the beginning of each interview. Personal identifying information was not recorded.

\section{Interviews and data analysis}

The interviews consisted of semistructured questions covering the following themes:

- Description and/or experience of certification and registration processes;

- Attitudes to and meaning of certification and registration;

- Role and relationships with relevant stakeholders (health, education, social services);

- Improving experiences and systems.

The nature of the interviews encouraged participants to feel comfortable to raise issues they felt relevant to their own experiences. ${ }^{25}$ The advisory group provided guidance on the interview questions' consistency, validity and ambiguity.

Each transcript was read and analysed multiple times. Interview data were analysed thematically, similar to previous research with adults. ${ }^{1} \mathrm{~A}$ list of deductive codes was initially created; inductive codes emerged during the second level of the thematic analysis. ${ }^{26} 27$

All interviews were digitally recorded with the participant's consent, lasted between 10 and $50 \mathrm{~min}$ and were transcribed verbatim. The interviews were completed between March and July 2014.

Extracts are referenced with the type of interviewee and interview number-parent (Par); ophthalmologist (Ophth); secretary/administrator (Adm); nurse (Nur); optometrist (Optom); eye clinic liaison officer (ECLO); orthoptist (orth); social services staff including managers, rehabilitation officers, administrators (SS) and QTVIs and a manager (QTVIs). The terms 'certification' and 'registration' were used inconsistently by most interviewees; hence these terms are amended in the text for clarity.

\section{RESULTS}

Interviewees

Seventy-eight participants were interviewed. Hospital interviews were with a range of staff involved in the certification process (see table 1). Of the 12 consultants interviewed, 10 were qualified for over 10 years, the remaining 2 consultants were qualified for over 5 years.

Twenty-seven per cent $(n=7)$ of parents stated they had an income below $£ 15000 /$ annum. Two parents (8\%) classified themselves as Asian, slightly below England's population of mixed, Asian, African-American and Chinese ethnicities which make up 12\% of England's population. ${ }^{28}$

Specialist education services in seven local authorities associated with the hospitals and representatives from seven social care departments were also interviewed. In one area, representatives from different social services and education departments were interviewed resulting in professionals from eight local authority areas being interviewed.

\section{Referral processes}

Across England, the typical patient pathway when an infant or child has a VI is a direct referral from health to education, usually via letter. Once a referral from the hospital is received by education, a QTVI makes initial contact, usually by telephone. All but one of the areas under analysis referred directly from hospital to

Table 1 List of interviewees

\begin{tabular}{|c|c|c|c|}
\hline $\begin{array}{l}\text { Hospital staff ( } 3 \text { teaching hospitals } \\
2 \text { district general) }\end{array}$ & Education & Social services & Parents \\
\hline $\begin{array}{l}12 \text { Consultant ophthalmologists ( } 8 \text { subspecialty } \\
\text { paediatric ophthalmologists) }\end{array}$ & 7 QTVI & 6 Managers & 26 Parents with 28 children \\
\hline 3 ECLOs & 1 Manager & $\begin{array}{l}5 \text { Rehabilitation } \\
\text { workers }\end{array}$ & $\begin{array}{l}22 \text { Severely sight impaired, } 6 \\
\text { sight impaired }\end{array}$ \\
\hline 1 Optometrist & & 3 Administrators & $\begin{array}{l}7 \text { Infants and children with } \\
\text { complex needs }\end{array}$ \\
\hline 5 Administrators & & 1 Social worker & $\begin{array}{l}18 \text { Diagnosed under age } 1 \\
10 \text { Certified under age } 1\end{array}$ \\
\hline 6 Orthoptists & & & Ethnicity: 26 white, 2 Asian \\
\hline 2 Nurses & & & 12 Girls, 16 boys \\
\hline Total: 29 & Total: 8 & Total: 15 & Total: 26 \\
\hline
\end{tabular}


education. In one area undergoing a lengthy reorganisation, QTVIs were not alerted when children were certified and stated 'it's a little bit hit and miss when we find out' (QTVI3).

Under Special Educational Needs and Disability legislation, an infant or child's entitlement to specialist educational support is entirely independent of whether or not they have a CVI. All QTVIs interviewed confirmed children do not need to be certified or registered in order to receive educational support.

(Certification and registration) doesn't open doors [to QTVIs]...we can offer all the resources and things whether they are registered or not. (QTVI2)

All parents interviewed stated the lead professional supporting their infants and children came from education rather than social care (where adults receive their support).

\section{Parents and ophthalmologists report different experiences}

The interviews found differences in opinions between the experiences of parents seeking support for their VI infants and children and ophthalmologists' stated practice. Parents stated they wanted referrals to education prior to diagnosis, but doctors appeared to wait until they had a firm diagnosis before referring. The offer of a CVI appeared to trigger ophthalmologists to refer to education services.

\section{Parents wait for diagnosis and offer of CVI before being referred}

Despite processes outlining that a CVI is not needed for an education referral, two-thirds of parents $(n=18)$ stated they were not referred to support until after the CVI was issued to their infants/children. These parents stated ophthalmologists delayed or did not mention either certification or referral to education until they had reached a firm diagnosis.

(Ophthalmologists) really didn't do a lot before (certification), that's what I'm angry about, those years before school, more wasn't done. Now when I look online and stuff you see all of these nursery schools for VI children and afternoon sessions and play sessions. There was none of that, I didn't know about any of that. (Par14)

One parent of a child diagnosed with idiopathic nystagmus at age 9 months waited until he was 3 to be certified, by this stage she had referred her child to a QTVI through her own networks and received no referrals to support or information about her child's VI from the hospital. In this case, certification was prompted only when the child participated in a research project and the research staff recommended it to provide additional support (Par6).

For some parents, the lack of referral or access to information had a lasting and significant impact on their lives. One parent was told by a paediatric ophthalmologist to treat their child eventually certified as sight impaired simply as 'a normal baby'.

The doctor at *** just said to me 'just treat him like a normal baby. Just carry on exactly like you are'...if they'd certified him and I had had proper advice they might've said to do as much as you can to stimulate him. She said just treat him like a normal baby...If he had been certified and I had spoken to a QTVI earlier and been given more advice. (Par14)

Education and social care professionals confirmed what parents had said-they often encountered children who were not referred to support until the CVI was issued or a firm diagnosis reached. One QTVI confirmed that some children go without support because they are not referred as ophthalmologists wait to see if vision improves. QTVIs stated infants and children with complex needs often presented late to their services.

it's often the more complex needs children that...we haven't had a referral to the service for, the education service and that is often because they are very young. (QTVI8)

\section{Ophthalmologists state referral is offered before certification}

While the majority of parents wanted support before certification, all 12 ophthalmologists, 3 ECLOs and 6 orthoptists stated they referred infants and children to QTVIs and education before they reached a stage where they offered certification.

You don't have to be certified to get access to the VI teaching service. So we're not depriving them of something by them not being certified...I don't leap in and certify until I absolutely know where they are going to end up. And I'm still going to do all the other things that I would do for them, referral for low vision aids, for to teaching service, specialist optometry and so on. It's on my list but I wouldn't say I, I personally don't leap in and certify early on. (Oph3)

Paediatric ophthalmologists with close relationships with QTVIs and education stated they frequently discussed cases with QTVIs.

The first thing we tend to do is refer to VI team, even before certification, so they have a little bit of input from this team before they actually get information about registration, education team, enhanced service...We rely on them heavily as well. (Oph2)

Other areas had internal systems, working closely with orthoptists to ensure children were offered support when they needed it.

We have a system where the orthoptist would see all those children as well and would normally make a referral to learning support services but as I say, we wouldn't certify them until their eye-sight deteriorates to appropriate standards...We're also going to be referring people who 
aren't certified, from that point of view they are equally going to have access to learning support. (Oph12)

\section{Reasons for differences between parents' and clinicians' experiences}

Numerous issues arose suggesting reasons for the dissonance between parents and ophthalmologists' experiences of referrals and certification. First, vision typically improves with age and it is standard practice for ophthalmologists to wait months, in some cases years, to identify a diagnosis.

It's not clear cut. Certain conditions where it is, there are certain where it isn't. Some children with delayed visual maturation, where you don't really know how much their vision will improve or to what level, so some of those it's quite a waiting game or you're not able to assess the child's vision very accurately. And so you're waiting for more accurate clinical information. (Orth4)

The difficulty in measuring visual acuity (VA) and VI in infants was mentioned by most ophthalmologists and many stated they waited to offer certification until they (or orthoptists) could measure VA or until test results were received.

It can be extremely difficult to measure visual acuity in very young children, small babies. So what may appear, for example, to be a non-seeing baby at 12 weeks with something like delayed visual maturation may actually turn out to be a baby with perfectly normal sight in six weeks, or it may be much longer. I think it's a delayed visual maturation if I think it's a baby with much more severe visual diagnosis then it's based on that. (Oph11).

What appears to be happening is that some ophthalmologists associate both the offer of certification and referral to support with determining a firm diagnosis.

This issue may be a particular problem in hospitals without paediatric ophthalmology specialist consultants. While this is a small sample, consultants working in different tertiary centres stated parents often arrived at their hospitals looking for support, having not been referred during their visit to the first hospital.

If you have (ophthalmologists) who do not have specialist training in paediatric ophthalmology they don't understand the pathways and the needs of the children and they don't think to refer them to the VI services and they don't think that a child can use a Low Vision Assessment and they don't think that actually the parents do actually need help filling in the Disability Living Allowance form. (Oph8)

Ophthalmologists who certified numerous children in a year had more flexible attitudes to certification and the Department of Health (DH) guidance.

I tend to be rather flexible with interpreting the guidelines. I don't think visual acuity is the best way of doing it in children. For instance, children with nystagmus might have better vision than $6 / 18$ but they obviously have visual problems in terms of tracking and visual perception. Same with some of the milder forms of cerebral VI where their visual acuity can be good but they are confronted with a real world where they are overloaded with visual information and they really struggle. I tend to adopt a more functional approach to it. Based on fact that acuity are guidelines rather than strict legal definitions. (Oph7)

While interpreting the DH guidance flexibly can benefit those on the borderlines or waiting for a diagnosis, it can also mean certification is offered inconsistently.

Another issue that arose was related to the offer of certification for children with complex needs. Some health professionals stated they delayed the offer of certification for these children because they felt their parents already had so much to deal with and the benefits of certification would not be worthwhile. Some ophthalmologists stated they believed parents of infants/children with complex needs might not want to discuss certification but made this assumption without actually discussing the offer with parents.

They've got multiple agency involvement it probably isn't very important to register that child if they are going blind...many of our children who need that are multiply handicapped are already getting a lot of support and I think they feel they just don't want another label. (Oph6).

\section{How to ensure early and consistent support} Multidisciplinary teams

Ophthalmologists stated working in multidisciplinary teams reduced possible delays in certification or referrals for support.

Many of our children come from multi-disciplinary teams where we supply staff to check vision for these children. (Oph6)

Across the eight local authority areas studied, four areas held joint meetings between health, education and SS, meetings were usually held once a term or a few times a year. These joint meetings facilitated relationships, making it easier for professionals to pick up the phone or send an email when there is a problem-or before an issue becomes a problem.

I don't think we could offer a good service if we didn't work together as a team. (Orth3)

\section{Direct referral pathways}

To encourage prompt and consistent referrals, two areas created referral forms to directly refer from health to education as children were getting lost in systems and referrals were not happening fast enough. 
We get parents to sign a consent form to say they are happy to share information so we can liaise quite easily. (Orth3)

The DH has a recommended pathway for referral prior to certification, using the Referral of Visual Impairment (RVI). Although designed primarily for use with adults, it can be used with children as well. This referral does not require the patient (adult or child) to be certified and registered. In interviews, the RVI was not mentioned once by ophthalmologists (although they were not directly asked if they used the RVI). Ophthalmologists referred to QTVIs and social care without the need for a RVI.

\section{Eye clinic liaison officers}

Intermediaries such as specialist nurses, ECLOs and Family Support Unit provided a reliable referral route for parents to education and other services for specialist support. Parents who attended children's hospitals, where most have roles such as ECLOs or Family Support Units, very much valued the information and support they offered.

When we had hospital appointments, we were up there quite a bit in the first few months...(ECLOs) would sit in on the appointments that we had...the information they first gave us, it was really helpful and it was nice to know someone was...We would've felt really isolated and not had a clue basically. I don't really know what we would've done. (Par22)

Ophthalmologists stated these intermediary roles could potentially solve many of the problems faced by parents of infants and children with VI in providing timely information and support.

I think ECLOs are one of the things that would really help transform care for children with VI over the years. (Oph5)

However, even when these personnel were in hospitals, referring to these intermediary roles was not consistent, instead it was a subjective decision made by ophthalmologists. Parents were very disappointed when children's hospitals/Centres of Excellence failed to provide support or information through these intermediary roles (as they were not referred). One parent, despite seeing orthoptists, consultants and optometrists at a children's hospital, did not receive the support she expected.

I was supposed to get a journal ${ }^{29}$ - from birth up to about five, about certain things you can do with blind children to help them. I never received it and they promised me it. (Par18).

\section{DISCUSSION}

\section{Delayed referrals are unnecessary}

The referral to specialist support was often unnecessarily delayed in the process of establishing a diagnosis. Even though most childhood visual disorders are present from infancy, our research confirmed there is often a 'prolonged period of uncertainty before the final diagnosis is achieved". ${ }^{13}$ Previous research found $21 \%$ of parents waited less than a month to have their child's VI diagnosed while $25 \%$ waited over a year. They also found $40 \%$ of children with multiple disabilities had to wait more than a year to have their VI diagnosed. ${ }^{14}$

The purpose of certification is to formally refer a person to social services; however, it should not be the only prompt to a referral. While the ophthalmologists who took part in this study were aware of the importance of speedy referral of infants and children to the specialist education service, evidence from parents indicates that this is not consistent across the country. Delays in referring to education may be due to doctors waiting to obtain a firm diagnosis; health staff not understanding the role of the QTVI (particularly ophthalmologists without a paediatric specialism and, therefore, an understanding that 'education' is not just about the school years); and a lack of clear referral processes in some areas.

For parents of infants and children with complex needs, the delays could be longer as children are not always referred to ophthalmology departments or offered eye examinations and vision assessment by other health professionals. VI in children with complex needs is often underidentified ${ }^{30}$ and can take some time to diagnose. ${ }^{13}$ The number of children with neurodevelopmental disorders is contributing to the increase in the prevalence of VI, ${ }^{31}$ yet diagnosing VI in infants and children with complex needs is more difficult too, and therefore this cohort is more likely to be overlooked. ${ }^{31} 32$ This suggests not all eligible infants and children are being certified and that they and their families may be missing out on important financial and practical support. Early support is crucial for infants and children with VI and their families, to support children's cognitive development, communication, social and independence skills. Referrals to the specialist teacher (QTVI) from the local authority education advisory service is not dependent on certification.

\section{Refer when support is needed, not when certification is offered}

The compassion shown by ophthalmologists, orthoptists, optometrists and ECLOs was clearly apparent, but this is not enough-these sentiments need to translate into actions, so that infants and children with VI are promptly and consistently referred to the support they need to secure the best start to their lives. There should be a formal mechanism for triggering QTVI and social care support even if there is uncertainty about diagnosis and prognosis, such as formal referral pathways. ${ }^{33}$ 
Previous studies found value in infants and children managed by multidisciplinary teams 'to ensure comprehensive and integrated intervention'. ${ }^{9}$ This research demonstrates the value of multidisciplinary teams as well as intermediaries to ensure referrals and support are offered to infants and children with VI.

A consistent mechanism for triggering educational and social support for children with VI and their families, even when diagnosis and eventual level of visual function are uncertain, would improve child development and families' experience.

\section{LIMITATIONS OF RESEARCH \\ Bias}

Overall, the number of participants interviewed in each category was small; as such, the findings should be considered indicative; however, saturation/repetition levels were reached in all interview groups, suggesting confidence in the findings. ${ }^{34}$ We sought to reduce the potential for selection bias by selecting from a broad group of parents; however, all children needed to be certified. We aimed to minimise reporting bias by defining the research questions at the beginning of the project and the researcher (TB) was experienced in the topic and with the interview population. ${ }^{1}$ In addition, the advisory group provided objective guidance in forming the research questions and in reviewing the findings.

\section{Sample}

The original aim of the research was to interview parents from the same areas as the professionals (similar to the sample researched for the adult research). ${ }^{1}$ As there are fewer infants and children certified compared with adults, it was decided to widen the sample to include all parents of infants and children certified in all parts of England. As such, it is difficult to provide a snapshot of each area. Despite this limitation, the research is able to identify key themes arising from each interview cohort.

In addition, other professionals involved in the certification and registration process were occasionally mentioned by interviewees (eg, community paediatricians, support workers delivering portage (home-visiting educational service for preschool children with additional support needs and their families)); however, they were not interviewed as the research focused on the key workers providing support and information to parents and carers of infants/young people with sight loss.

Twitter Follow Tammy Boyce at @tamboyce

Acknowledgements The authors thank the parents, health and social care professionals and QTVIs who were involved in this research, as well as members of the Advisory Group.

Contributors TB wrote the initial draft. All authors revised the initial draft and subsequent drafts. TB is the guarantor. All authors have full control of the content of the article.

Funding The Royal National Institute of Blind People funded this research. The funders contributed to the design of the research.
Competing interests None declared.

Provenance and peer review Not commissioned; externally peer reviewed.

Data sharing statement No additional data are available.

Open Access This is an Open Access article distributed in accordance with the Creative Commons Attribution Non Commercial (CC BY-NC 4.0) license, which permits others to distribute, remix, adapt, build upon this work noncommercially, and license their derivative works on different terms, provided the original work is properly cited and the use is non-commercial. See: http:// creativecommons.org/licenses/by-nc/4.0/

\section{REFERENCES}

1. Boyce T, Leamon S, Slade J, et al. Certification for vision impairment: researching perceptions, processes and practicalities in health and social care professionals and patients. BMJ Open 2014;4:e004319.

2. Williams $\mathrm{C}$, Northstone $\mathrm{K}$, Borwick $\mathrm{C}$, et al. How to help children with neurodevelopmental and visual problems: a scoping review. $\mathrm{Br} J$ Ophthalmol 2014;98:6-12.

3. Bonnier C. Evaluation of early stimulation programs for enhancing brain development. Acta Paediatr 2008;97:853-8.

4. Fazzi E, Signorini SG, Bova SM, et al. Early intervention in visually impaired children. Int Congress Series 2005;1282:117-21.

5. Tadic V, Pring L, Dale N. Attentional processes in young children with congenital visual impairment. Br J Dev Psychol 2008;12:491-502

6. Metsiou K, Papadopoulos K, Agaliotis I. Adaptive behavior of primary school students with visual impairments: the impact of educational settings. Res Dev Disabil 2011;32:2340-5.

7. Ely MS. Effective strategies for preschool peer group entry: considered applications for children with visual impairments. $J$ Vis Impairment Blindness 2014:287-97.

8. Rahi JS, Manaras I, Tuomainen $\mathrm{H}$, et al. Meeting the needs of parents around the time of diagnosis of disability among their children: evaluation of a novel program for information, support, and liaison by key workers. Pediatrics 2004;114:e477-82.

9. Solebo AL, Rahi J. Epidemiology, aetiology and management of visual impairment in children. Arch Dis Child 2014;99;375-9.

10. Rahi JS, Cable N. Severe visual impairment and blindness in children in the UK. Lancet 2003;362:1359-65.

11. Roe J. Social inclusion: meeting the socio-emotional needs of children with vision needs. Br J Vis Impairment 2008;26: 147-58.

12. Molden $\mathrm{H}$. A phenomenological investigation into the impact of parenthood: giving a voice to mothers with visual impairment in the United Kingdom. Br J Vis Impairment 2014;32:136-47.

13. Rahi JS, Manaras I, Tuomainen $\mathrm{H}$, et al. Health services experiences of parents of recently diagnosed visually impaired children. Br J Ophthalmol 2005;89:213-18.

14. Jepps C, Bacon J. Children and young people research. London: Blind Children UK, 2014.

15. RNIB. Benefits for families and carers. http://www.rnib.org.uk/ information-everyday-living-benefits-and-concessions/ benefits-families-and-carers (accessed 3 Aug 2015).

16. Department of Health. Certificate of Vision Impairment: explanatory notes for consultant ophthalmologists and hospital eye clinic staff. https://www.gov.uk/government/uploads/system/uploads/attachment data/file/213286/CVI-Explanatory-notes-in-DH-template.pdf (accessed 3 Aug 2015).

17. Mitry D, Bunce $C$, Wormald $R$, et al. Childhood visual impairment in England: a rising trend. Arch Dis Child 2013;98:378-80.

18. Malik AN, Bunce C, Wormald R, et al. Geographical variation in certification rates of blindness and sight impairment in England, 2008-2009. BMJ Open 2012;2:pii: e001496.

19. Kliner M, Fell G, Pilling RF, et al. Visual impairment in children. Eye (Lond) 2011;25:1097.

20. Certificate of Vision Impairment. Department of Health. https://www. gov.uk/government/uploads/system/uploads/attachment_data/file/ 213286/CVI-Explanatory-notes-in-DH-template.pdf (accessed 3 Aug 2015).

21. The Health and Social Care Information Centre. Registration data: registered blind and partially sighted people year ending 31 March 2014. NHS: The Health and Social Care Information Centre. http:// www.hscic.gov.uk/catalogue/PUB14798 (accessed 3 Aug 2015).

22. Morse JM. Biasphobia. Qual Health Res 2003;13:891-2.

23. Bryman A. Social research methods. 4th edn. Oxford: OUP, 2012.

24. Health Research Authority. Defining Research. http://www.hra.nhs.uk/ documents/2013/09/defining-research.pdf (accessed 3 Aug 2015). 
25. Corbetta P. Social research theory, methods and techniques. London: Sage Publications, 2003.

26. King N, Horrocks C. Interviews in qualitative research. London: Sage Publications, 2010.

27. Maxwell JA. Qualitative research design. An interactive approach. 2nd edn. London: Sage Publications, 2006.

28. Office for National Statistics. Population estimates by ethnic groups, current estimates, population estimates by ethnic group mid-2009 for primary care organisations. http://www.ons.gov.uk/ons/taxonomy/ index.html?nscl=Population+Estimates+by+Ethnic +Group\#tab-data-tables (accessed 3 Aug 2015).

29. The Early Support Developmental Journal for Babies and Children with VI. http://www.councilfordisabledchildren.org.uk/media/552269/ developmental_journal_for_babies_and_children_with_visual_ impairment.pdf (accessed 3 Aug 2015).
30. Little JA, Saunders KJ. A lack of vision: evidence for poor communication of visual problems and support needs in education statements/plans for children with SEN. Public Health 2015;129: 143-8.

31. Rahi JS, Cumberland PM, Peckham CS. Improving detection of blindness in childhood: the British Childhood Vision Impairment study. Pediatrics 2010;126:e895-903.

32. Flanagan NM, Jackson AJ, Hill AE. Visual impairment in childhood: insights from a community-based survey. Child Care Health Dev 2003;29:493-9.

33. See for example. http://www.ukvisionstrategy.org.uk/get-involvedways-get-involved-across-uk/children-young-peoples-guidelines; http://www.vincyp.scot.nhs.uk/pathway/ (accessed 3 Aug 2015).

34. Kuper $A$, Lingard L, Levinson W. Critically appraising qualitative research. BMJ 2008;337:a1035. 